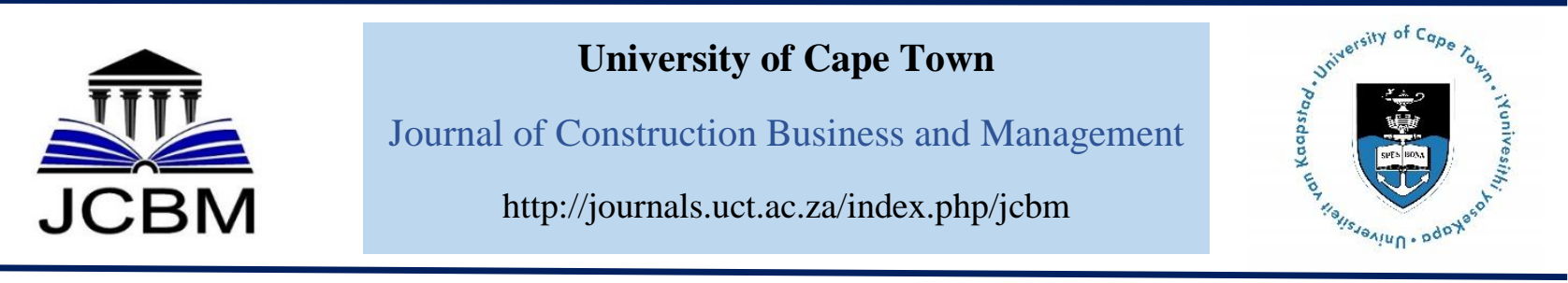

\title{
Effect of Management Strategies in Entrenching Organisational Safety Culture in the Electricity Industry of Zambia
}

\author{
E. M. Mwanaumo ${ }^{1}$ and M. Mambwe ${ }^{2}$ \\ $1 \& 2$ Department of Civil and Environmental Engineering, School of Engineering, University of Zambia, Great East Road \\ Campus, Lusaka, Zambia
}

Received 7 June 2018; received in revised form 23 October 2018 and 28 December 2018; accepted 10 January 2019. https://doi.org/10.15641/jcbm.3.1.2019.598

\begin{abstract}
Entrenching safety cultural aspects is one of the functional areas within the management system that underlines various strategies. A number of investigations in the electricity industry revealed that a deficiency of organisational safety culture is one of the underlying causes of accidents. This study sought to determine management strategies that impact organisational safety culture in the electricity industry in Zambia. The objectives underpinning the study include establishing management strategies that affect organisational safety culture, assessing worker's knowledge on safety, health and environmental (SHE) programs, and ascertain the effect of organisational safety culture on workers attitude towards safety. Various literature was reviewed on management strategies. The research used the quantitative method in which descriptive and analytical survey methods using one-way analysis of variance (ANOVA) as inferential statistics. A structured questionnaire to obtain data was designed, and the multiple linear regression method to analyse data in order to meet the research objectives was applied. The study selected 230 workers from companies within the electricity industry using simple random sampling while 170 questionnaires were completed, giving a response rate of $73.91 \%$. Findings revealed that workers understand organisational safety culture and SHE processes; while management strategies such as recruitment, and rewards and compensation, had a significant influence on organisational safety culture. The study concluded that management commitment and their involvement in the safety aspects of the electricity industry is not just a benevolent obligation, but it compels and motivates the workers they protect to achieve organisational objectives and goals. Furthermore, the study recommended the restructuring of processes during induction and orientation to maintain high levels of safety at workplaces in order to record few workplace accidents.
\end{abstract}

Keywords: Electricity Industry, Entrenching, Management Strategies, Organisational Safety Culture

\section{Introduction}

SHE management has historically been very responsive in the electricity industry, with measures of improvement only happening after root causes of major incidents have been established. Organisational safety culture has the capacity to create a cohesiveness that cultivates growth and give distinctiveness by providing standards that allow a variety of approach in an organisation (Mwanaumo \& Thwala, 2011). According to the United Nations, Safety at work is not only a sound economic policy but also a basic human right which can be achieved through culture (WHO, 2006). This is an important statement that encourages the need to employ safety policies world over, as a human right.

${ }^{1}$ Corresponding Author.

Email address: erastus.mwanaumo@unza.zm
Rendering Du Toit (2012), on operational safety culture in the organisation, he postulated that development of humanity could enable the magnitude of threats in a workplace. Further, several studies have been undertaken that conclude that organisational safety culture in any industry is an imperative element to SHE management that ascertains the significance of noticeable engagement of top management in heightening the adoption of safety culture by workers (Kwayisi, 2014: 36).

According to Son (2016), organisational safety culture has increasing prominence and acceptance as one of the essential elements in the management of risks in large and complex engineering systems. As a result of the relatively high magnitude of consequences which are synonymous with high hazardous industries, a strong emphasis is 
placed on development of an excellent safety culture within an organisation (Olusuyi, 2011). Entrenching safety cultural aspects is one of the salient functional areas of the majority of management systems, with strategies aimed at establishing key frameworks ranked amongst the top priority of management. The electricity industry is one such industry that is synonymous with issues of safety culture due to the dynamic nature of operations undertaken, coupled with a high level of risk.

Aspects of organisational behaviour that are related to culture are normally unnoticed and their impact on organisational safety culture underrated. In entrenching organisational safety culture in the electricity industry, management involvement and its commitment to ensuring safety values are maintained as one of the factors to organisational safety culture as postulated by Mihai and Sorin (2010: 305). Implicitly, a relationship exists between management commitment and safety performance even though it warrants further research (Kwayisi, 2014).

In Agbola (2012: 54) organisational safety culture is considered as a subset of organisational culture and is focused on commonalities among attitudes to safety. Organisational safety culture was also paraphrased by Zou and Sunjino (2015) that it includes shared values at the group level, formal safety issues attributed to an organisation, linkages related to management and supervisory systems that emphasises the contribution of all organisational partakers, has a positive effect on workers' behaviour, and involves reward and durability.

According to the Auditor General's Report on the Management of Occupational Health and Safety in Zambia presented during the Fifth Session of the Eleventh National Assembly (2015), the rise in the number of occupational accidents in high-risk industries such as the electricity industry could be attributed to lack of strategies by organisations used to reduce the risk of incidences. The report further indicated that there was need for top management to come up with strategies that can be implemented within such organisations to curb the rise in accidents and create a culture of safety.

Additionally, according to the Energy Regulation Board (ERB) Report of Zambia (2014) most electrical accidents result from unsafe equipment or installation, unsafe environment, or unsafe work practices. Investigations into these accidents identified that some of the causes of injuries and fatalities are related to the safety perception and include factors such as faulty insulation, improper grounding, loose connections, defective or wrong parts, unguarded live parts, and failure to deenergise electrical parts before inspection or repair, improperly maintained electrical tools and equipment, failure to exercise caution when working, exposed energised lines and equipment, and using inappropriate personal protective equipment and insulated tools.

Further, ZESCO Limited, a government-owned entity, experienced a lot of work-related accidents attributed to SHE in the first quarter of 2016 indicating $38 \%$ of the total incidences in the industry this is according to the report by the Worker's Compensation Fund Control Board (WCFCB). These incidences caused electrocutions, road traffic accidents, fall from a height, electrical burns/flashes, hit/struck by an object, material/manual handling and caught-in-between and disease contracted during employment. Another analysis of data obtained from WCFCB revealed that the rate of fatalities arising from workplace accidents rose from 67 to 127 cases in 2011 and 2014 respectively representing an increase of $65 \%$ in the period under review (WCFCB, 2016).

Furthermore, during the 2019 National Budget presentation on 28 September 2018 to the Zambian Parliament, it was mentioned that the Government had planned to recruit over 1,000 Safety Inspectors in the Ministry of Labour and Social Security in order to closely monitor high risk industries on issues related to SHE and help organisations formulate strategies, policies and procedures that can be used to curb accidents and promote employee welfare. This pronouncement is an indication that the Zambian Government was ready to work with the industries in making sure accidents are reduced by helping promote strategies at a national level that can be adapted to stimulate organisational safety culture. Similarly, highrisk industries can develop roadmaps and plans that would be a basis in formulating strategies to organisational safety culture.

Given the above, management strategies are required and important to achieve organisational objectives aligned with the national strategies on safety. Therefore, the objectives of the study was to establish management strategies that have a positive effect on promoting organisational safety culture; to assess worker's knowledge of SHE programs; and to establish the effect of organisational safety culture on workers' attitude towards safety.

The study findings will contribute to the Zambian electricity industry safety performance by proposing strategies to promote organisational safety culture to the Department of Occupational Health and Safety in the Ministry of Labour and Social Security, and industry organisational top management. Furthermore, the research results shall be of great significant in illustrating the effects, whether positive or negative, of the strategies employed specific to the organisation according to the policies.

\section{Overview of Organisational Safety Culture and Management Strategies}

\subsection{Organisational safety culture}

Organisational safety culture as designated by Dumas (2011) is a constituent of the general philosophy of an organisation that affects the attitudes and beliefs of the workers regarding health and safety routine. Although there is no treaty on organisational safety culture definition, various definitions with similar elements have emerged over the years within the literature such as Dumas (2011) and Zou and Sunjino (2015). These elements include attitude, behaviour and perception of workers in an organisation which make them realise that safety is a priority. Choudhry et al., (2007) further described organisational safety culture as: Learned behaviour and those beliefs in the necessity, practicality and effectiveness of controls, attitudes and risk perception which makes people think safely and trust in safety measures or characteristics and attitudes in an organisation resulting in safety issues being a priority. 
Additionally, according to Guldenmund (2007), organisational safety culture are aspects of the organisational culture that have a future impact on attitudes and behaviour and values to increase or decrease safety risks.

\subsection{Organisational safety culture in the electricity industry}

Organisational safety culture lies in the heart of effective management of all risks related to the electricity industry such as major accidents and hazards according to Olusuyi (2011: 3) and is understood to be a major pointer to safety performance as indicated by Wachter and Yorio (2014: 119). Organisations have programs they can use to improve organisational safety culture in order to reduce costs and increase performance (Haukelid, 2008). Subsequently, some of the accidents in the electricity industry can be reduced through appropriate safe working behaviour (Hopkins, 2006). Accumulation of errors, questionable decisions, and misguided priorities placed ahead of safety, results in accidents. Nonetheless, causes of most accidents are ascribed to human error, and as suggested by most researchers in this knowledge area, $85 \%-98 \%$ of injuries that occur at workplaces are caused by unsafe attitudes (Williamsen, 2007: 19). Workers' unsafe acts are postulated to be the cause of about $88 \%$ of industrial accidents and that organisational failures are the underlying factors in individual action-oriented errors (Carrillo, 2010: 50).

Most studies reviewed in the Sub-Saharan regions have applauded the need for management to create strategies that would increase the levels of safety awareness and encourage organisational safety culture. However, the studies reviewed are not specific to the electricity industry but inclined to other industries such as mining, construction and aviation. In the study by Akpan (2011) on effective health and safety management policies for improved performance in organisations in Africa, he mentioned that there was a need for management to be the driver for effective health and safety. Some of his findings can be used in the electricity industry since most of the safety problems in the region are similar regardless of the sector. Additionally, AsieduAppiah et al. (2013) whose study was specific to the mining industry indicated the importance of management involvement in formulating SHE strategies. Other proponents for using management strategies such as policies and procedures, training and worker involvement in uplifting organisational safety culture in organisations in the construction and health industry include Mwanaumo and Thwala (2011) in Botswana and Kwayisi (2014) Ghana.

On the other hand, in some organisations within the electricity industry in Zambia, management are disconcerted with issues of safety. This assertion is supported by Asiedu-Appiah, et al. (2013) who opined that responsibilities in coordination and planning of organisational safety cultural aspects in the electricity industry had no clear-cut and that adherence to SHE laws and regulations were generally low. Kilian (2012) further espoused that management requires that it champions organisational safety culture as they have a significant role to play through administering, communicating, facilitating and supporting the process.

A report prepared by the Kafue Gorge Regional Training Centre (2014: 5) showed that safety programs were not highly recognized especially in the distribution divisions of the electricity sector. This report recommended that there was need for management, especially in distribution facades to adopt organisational safety culture as a key function and hence establish safety programs. This gap could be ascribed to a lack of safety policy at the time, to provide the direction needed for the framework and successful implementation of safetydriven culture.

\subsection{The role of management strategies in organisational safety culture}

In the perspective of the organisational safety culture of an organisation, participation of top and middle management denotes the extent to which individual workers get involved with critical safety activities (Dumas, 2011). According to Mambwe and Mwanaumo (2017: 567), these safety activities include management presence, collaboration and interaction of managers at safety seminars, SHE Circles (Safety Tool Box), Green Area Meetings, and ability to stay in-touch with risks relevant to the day to day operations with the workers.

The Occupation and Safety Act No. 36 (2010) requires an employer to ensure all workers implement safety and health strategies. This ensures that Safety Managers assist in the implementation and management of SHE programs, processes and strategies of an organisation and are responsible for the maintenance of safety records, coordinating induction and orientation on SHE for new and existing workers, accident investigation, communication and information materials on safety.

Tan and Nasurdin (2011: 157) aver that management strategies are aligned to specific strategies, attitudes and policies planned to motivate, attract, develop and retain workers to ensure the effective operation and survival of an organisation. In effect, SHE policies are intended to improve and maintain a safety cultural environment that prevents and reduces potential risks, and workplace hazards. Management strategies impact the operation of the organisation in terms of safety and health management as postulated by Asiedu-Appiah et al. (2013: 32). As functional areas of management in ensuring organisational safety culture, they included training and development, recruitment and selection, information and communication and performance management, as paramount strategies.

However, Akpan (2011: 162) expounded numerous ways of edifying organisational safety culture which include management leadership and organisational commitment, roles and responsibilities, employee participation in hazard identification and assessment process, determination of controls, enforcement of controls and emergency response plans. While the management commitment is acknowledged as very contributory, Mihai and Sorin (2010: 303) in their study specified that managers had limited understanding of both their legal and corporate responsibilities on safety and health and on ensuring a hazard-free workplace environment. 
The account of the problem can be derived from the fact that several studies have been conducted on organisational safety culture in the electricity industry in Zambia and have overlooked the roles and strategies that key players such as safety managers and top management add to the implementation of an organisational safety culture. Management formulates appropriate policies on safety and health, and environmental management systems by making sure there is a conducive atmosphere for safety at work. Nonetheless, according to the Auditor General's Report on Occupational Health and Safety (2015), Zambia has seen an increase in fatalities in the industry arising from workplace accidents. The increase was from 67 to 127 cases from 2011 to 2014 representing an increase of $65 \%$. This led to a public outcry on the need to improve occupational safety and health conditions and to introduce strategies that can be used to curb accidents and help reduce fatalities.

Hence, as can be seen from the empirical studies undertaken, the lack of literature on management strategies in entrenching a safety-driven culture necessitated this study. Therefore, the objective of the study was to assess the effect of management strategies in entrenching a safety-driven culture in the electricity industry of Zambia in order to reduce workplace accidents. Furthermore, the study determined management strategies that have an impact on organisational safety culture, assessed worker's knowledge on SHE programs and established the effect of organisational safety culture on workers. The study adopted six themes as management strategies that can be used in entrenching organisational safety culture according to Asiedu-Appiah et al. (2013), Iqbal et al. (2015) and Byers and Rue (2011: 325).

\section{Research Methodology}

The study adopted a quantitative research approach and descriptive survey in which both primary and secondary sources of data were used in assessing management strategies. According to Weigmann et al. (2004), quantitative approaches especially surveys of individual responses, are more practical in terms of time and costeffectiveness. Primary sources of data were collected using a structured questionnaire as a research instrument, while secondary sources of data such as articles, statutes, journals and past researches, were also reviewed in the study as applauded by Machabe and Indermun (2013) of South Africa. According to Guldenmund (2010), as cited by Ganson (2014), organisational safety culture is normally assessed or measured by conducting questionnaire surveys among a group of workers in an organisation. The study utilised a descriptive survey research. Leedy and Ormrod (2015) postulated that descriptive surveys could be used as a means to collect data from the questionnaire. The survey in this study involved asking workers to complete a designed pretested specific, standardized questionnaire which was administered to provide the respondent with an opportunity to give their perceptions on certain health and safety related dimensions, and as such, this method was considered for data collection and analysis purposes.
The study respondents comprised of technicians, engineers, safety managers, supervisors, and maintenance managers, senior managers and top managers from the electricity companies in Zambia that were categorized as government owned and privately-owned organisations. The sampling techniques adopted in the study were for purposes of selecting respondents strategically designated based on the roles they play within the electricity industry. Hence, simple random sampling techniques and purposive sampling techniques were applied. According to Davies (2007) and Saunders et al. (2009) purposive sampling helps the researcher identify and target individuals that will be typical candidates of the population under review. Distributed questionnaires were 230, of which 170 usable responses were received, while 35 (15.22) were either incomplete or spoiled, which gave a response rate of $73.91 \%$ and included usable questionaires and was onsidered as being close to the acceptable range of $80 \%$ as reported by Branson et al., (2017). The remaining 25 (10.87\%) questionnaires were not recovered or responded. Statistical Package for Social Science (SPSS) and Microsoft Excel software were applied to analyse the data through the use of descriptive statistics and linear regression models.

Mojapelo et al. $(2016 ; 106)$ applied seven dimensions to explore perceptions of employees in the steel industry towards occupational health and safety standards in the manufacturing industry in South Africa, in order to tailor a structured questionnaire distributed to a purposive sample of 165 employees. The results revealed that employees perceived occupational health and safety standards as satisfactory in all seven-occupational health and safety dimensions adopted as independent variables for the multiple linear regression analysis to assess the data. These were (1) information and training, (2) health and safety awareness, (3) employee behaviour (4) role of the supervisor, (5) health and safety reporting mechanisms, (6) workplace inspection, and (7) workplace environment. Conversely, Mojapelo et al.'s (2016) study was focused on employees, while the present study was more focused on management strategies.

However, to assess the effect of management strategies in entrenching organisational safety culture, the current study espoused six themes as safety dimensions and human resource strategies as applied by Akpan (2011). These include (1) Recruitment, (2) Training \& Development, (3) Performance Analysis, (4) Communication, (5) Induction \& Orientation, and (6) Reward \& Compensation. These dimensions were applied as independent variables to create a multiple linear regression model, while organisational safety culture was applied as a dependent variable.

Additionally, Davids (2016) undertook a study using the 5-point Likert scale to respond to 49-item statements by choosing one answer per statement. The results indicated that a highly positive correlation was found to exist between the themes of organisational commitment and management involvement. The study, therefore, adopted the use of a 5-point Likert scale. Several studies have indicated the use of a 5-Point Likert scale in the study of organisational safety culture. The scale allows the respondents to express how much they agree or disagree with a particular statement on the questionnaire, 
the scale is also easily understood, and responses are easily quantifiable and subjective to the computation of some mathematical analysis (Leedy \& Ormrod, 2015).

\section{Demographic Distribution of Questionnaire Respondents}

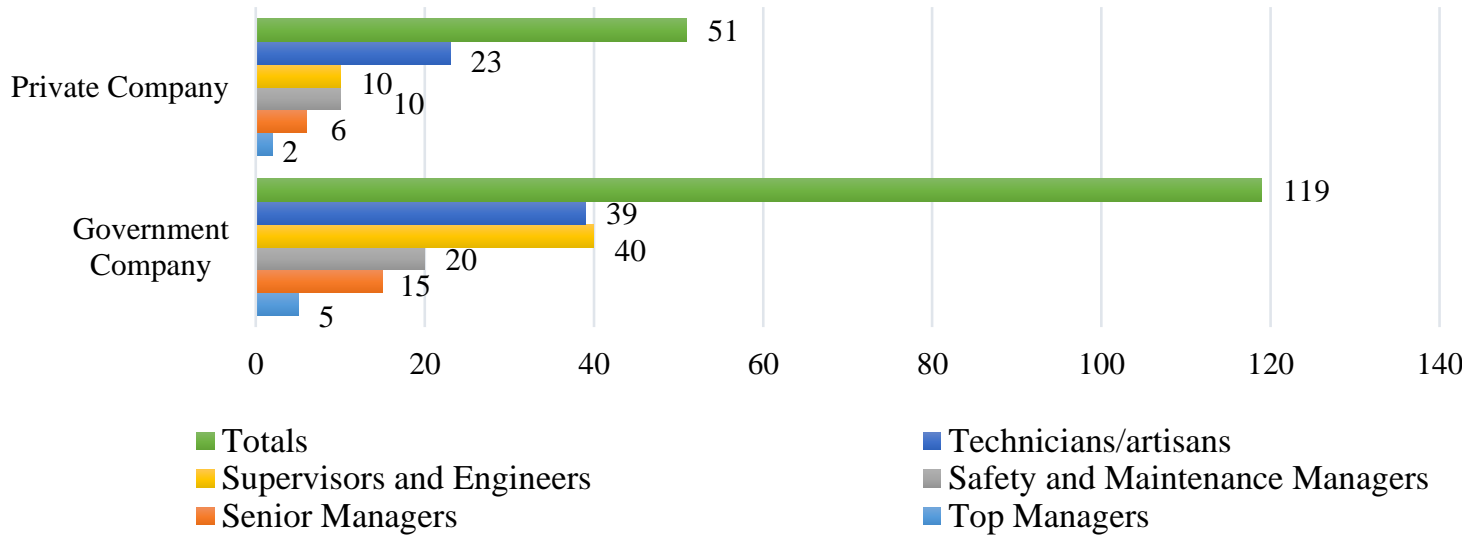

Figure 1: Demographic Distribution of Questionnaire Respondents

According to Mason et al. (1989), descriptive statistics are used to summarise data, hence considering that the sample size was 170 , the parametric test was carried out for normality (Motulsky, 2005). Trochim (2004) indicates that reliability is established when the data is collected from the correct sources through the appropriate method. Therefore, it was considered that the government and private employees working in the electricity industry provided reliable answers to the questions on the effect of management strategies on organisational safety culture.

The research also centred on capturing the relationships that exist between management strategies and organisational safety culture, in order to conceptualise the study. The relationship that exists is inversely proportional, in that when strategies such as the right recruitment of staff, training and development on SHE, performance analysis, enhanced communication, induction and orientation, and rewards and compensation, are implemented, the rate of incidents, environmental risks and occupational health diseases are reduced. Once these measurements are reduced, safety culture in the organisation is increased affirmatively. Correspondingly, when worker's knowledge on issues of SHE is enhanced, organisational safety culture is increased and inversely affects the rate of safety incidents positively by reducing the risks. Similar accessions were also postulated by Agba (2012), Du Toit (2012) and by Wachter and Yorio (2014). In all instances, organisational safety culture was dependant on management strategies and worker's knowledge of safety which are independent variables.

Further, Guldenmund (2007) and Carrillo (2010) acknowledged that when organisational safety is enhanced, workers attitude towards safe work is enhanced. This study conceptualizes that there is a direct interaction between organisational safety and the dependent variable, workers attitude towards safe work as illustrated in Figure 2.
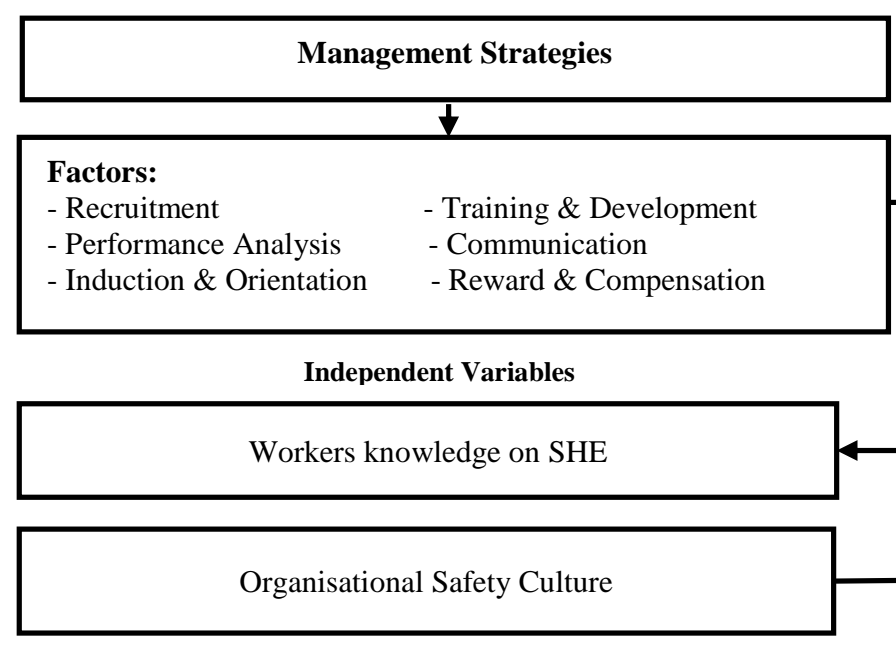

Independent Variable

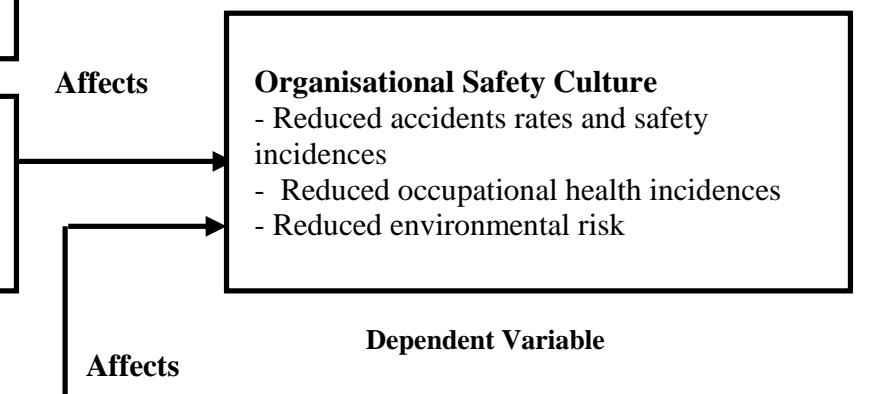

Worker's attitude towards safety (Positively)

Impacts

Dependent Variable

Figure 2: Conceptual framework - effects of management strategies in entrenching organisational safety culture (Author, 2018) 


\section{Findings and Discussion}

\subsection{Demographic profile of respondents}

This section analysed the respondent's demographic information by use of percentages based on counts and charts that were undertaken. The demographic profile of respondents used was educational attainment of respondents and the position or grade held at the workplaces.

\subsubsection{Descriptive analysis of respondents' educational attainment}

To establish the educational attainment levels of the workers in the electricity industry of Zambia as recorded across the survey's respondents. According to Table 1, it was found that the highest educational attainment was that of a Doctorate which constituted $1 \%$ of the entire electricity organisations respondents that took part in the study and then from Master's degree, Bachelor degree, Diploma, and Certificates holders, as the most attained level of education.

Table 1: Educational attainment of respondents

\begin{tabular}{lcc}
\hline & Sum & Percentage \\
\hline PhD & 2 & 1.18 \\
Masters & 46 & 27.06 \\
Bachelor & 55 & 32.35 \\
Diploma & 50 & 29.41 \\
Certificate and others & 17 & 10 \\
\hline Totals & $\mathbf{1 7 0}$ & $\mathbf{1 0 0}$ \\
\hline
\end{tabular}

Among these qualifications, most of the workers indicated to have a Bachelor's Degree (32.35\%) and a Diploma $(29.41 \%)$. With regards to work experience, the results indicated that most of the workers had experience for over nine (9) years while those who worked less than three (3) years, were a smaller group. With more qualified workers and reasonable experience in the electricity industry, it can be deduced that the composition of workers are more experienced and understand the management strategies in entrenching organisational safety culture in the electricity industry in Zambia.

\subsubsection{Analysis of respondents' grade/position at the workplace}

For easy reference, respondents were grouped into three categories, senior management, junior management and unionised workers. The senior management category comprised of principal and chief engineers, managers, senior managers and directors. Junior management staff included engineers, support staff with degrees, senior officers, superintendents and supervisors. Most unionized workers were made up of foremen, technologists, artisans, linesmen, and daily casual of employees. The senior management represented $23.2 \%$ of the total respondents, while junior management and unionized workers represented $56.4 \%$ and $20.4 \%$ respectively. The study incorporated the position of the workers during the questionnaire survey to understand the roles and responsibilities of each rank and how they would affect the management strategies that management and supervisors use to support organisational safety culture.

\subsection{Central Tendencies Measurement}

Measurement of central tendency using a mean of the various themes in the questionnaire was analysed. According to Son (2016), most of safety culture measurement tools employ 5-point Likert scale. David (2016) undertook a study using the 5-point Likert scale to respond to 49-item statements by choosing one answer per statement. His results indicated that a highly positive correlation was found to exist between the themes of organisational commitment and management involvement. Therefore, based on those mentioned above, the study adopted the use of a 5-Point Likert scale with five scales of intervals that ranged from strongly agree (SA) to strongly disagree (SD). The view of respondents on organisational safety culture knowledge from respective workplaces and departments was gathered to measure the level of exposure on the strategies on SHE management.

Table2: Statistical interpretation of knowledge on organisational safety culture

\begin{tabular}{|c|c|c|c|c|c|c|c|}
\hline & $\begin{array}{l}\text { Strongly } \\
\text { Agree } \\
(\%)\end{array}$ & $\begin{array}{l}\text { Agree } \\
(\%)\end{array}$ & $\begin{array}{l}\text { Neutral } \\
\quad(\%)\end{array}$ & $\begin{array}{l}\text { Disagree } \\
\quad(\%)\end{array}$ & $\begin{array}{l}\text { Strongly } \\
\text { Disagree } \\
(\%)\end{array}$ & $\begin{array}{l}\text { Mean } \\
(\mathrm{N})\end{array}$ & $\begin{array}{c}\text { Rank } \\
(\mathrm{N})\end{array}$ \\
\hline $\begin{array}{l}\text { I understand safety and health issues as required in } \\
\text { OSH Act } 36 \text { of } 2010 \text { and Factories Act, Cap. } 441 \text { of } \\
\text { the Laws of Zambia }\end{array}$ & 24.9 & 52.4 & 12.1 & 5.7 & 4.9 & 2.33 & 2 \\
\hline $\begin{array}{l}\text { Provision of significant updates on knowledge on } \\
\text { SHE. }\end{array}$ & 8.5 & 35.6 & 32.1 & 18.7 & 5.1 & 2.71 & 1 \\
\hline $\begin{array}{l}\text { Non-conformance to safety procedures lead to } \\
\text { punishment. }\end{array}$ & 22.6 & 56.2 & 11.5 & 8.2 & 1.3 & 2.12 & 4 \\
\hline $\begin{array}{l}\text { Unsafe workplace and environment gives me the right } \\
\text { to refuse to work }\end{array}$ & 33.2 & 26.2 & 29.1 & 8.2 & 3.3 & 2.17 & 3 \\
\hline $\begin{array}{l}\text { Management understands the risks associated with } \\
\text { operations. }\end{array}$ & 32.1 & 48.0 & 12.4 & 2.9 & 4.6 & 1.90 & 6 \\
\hline $\begin{array}{l}\text { Management and the workforce work together to } \\
\text { tackle safety issues. }\end{array}$ & 23.5 & 38.6 & 11.4 & 14.1 & 12.4 & 1.91 & 5 \\
\hline
\end{tabular}

Scale denotation: Likert Scale: 1 = Strongly agree to $5=$ Strongly disagree

Overall mean score $=2.43$ 
Management strategies in inculcating organisational safety culture are very critical when addressing SHE adherence. The overall mean score for the scale was 2.43 indicating a moderate inclination to the "agree" scale. The mean scores in this study ranged from $1.90-2.71$ As indicated in Table 2 the theme with the highest mean score of 2.71 ranking is "Provision of significant updates of knowledge on SHE". This represents a stronger inclination towards 'agree' position on the Likert scale. The higher mean scores demonstrate that management provides significant updates of knowledge on SHE and can be deduced that employees have significant knowledge and understanding on SHE. While the lowest mean score value of 1.90 was found to be "management understands risks associated with operations". This can be deduced that management takes time to understand the risks that the operations of the electricity industry bring about and hence lie in the category of strongly agree on the Likert scale. From the above, it can be deduced that workers that took part in the survey appreciably understand and have knowledge on safety and health and the role that management play in driving an organisational safety culture in the industry. Furthermore, this finding was supported by the research undertaken by Nunez and Villanueva (2011) who affirmed that there is a direct relationship between management involvement, safety risks and safety knowledge/awareness to lower the occurrence of accidents. If workers did not have the knowledge required, as postulated in the OSH Act 36 of 2010 and Factories Act, Cap 441 of the Laws of Zambia, working under a congenial environment that is safe would not be possible.

In assessing the knowledge that workers had pertaining to organisational safety culture about SHE operations of the electricity industry, it was found that $70 \%$ of the workers had a good understanding of the ascription made in the OSH Act 36 of 2010 and the Factories Act, Cap 441 of the Laws of Zambia. They also corresponded to have been involved in the SHE aspects. Additionally, it was disclosed that workers are involved in the provision and updates regarding knowledge on SHE aspects of the organisations they represent. This was an attestation of knowledge on safety and health activities at various workplaces in the electricity industry.

\subsection{Respondents views analysed inferentially}

Statistical inferential techniques were used to analyse the data drawn from the questionnaire survey in order to determine the Analysis of Variance (ANOVA) and model of Multiple Linear Regression to quantify the effect of management strategies on organisational safety culture entrenchment in the electricity industry as perceived by the workers. According to Leedy and Ormrod (2015), normally distributed data that can use the one-way or twoway ANOVA test are parametric. Moreover, the data fitted the normal distribution by assuming normality. Justifiably, the use of the one-way ANOVA indicates that there were no outliers in the data set. The use of ANOVA based on the literature reviewed in the study was applied by Davids (2016) who assessed safety culture of professional pilots within the aviation industry, and his results indicated assumed normality after testing using a one-way ANOVA with a size of over 100 respondents. Similarly, tests were used by Mojapelo et al. (2016) whose test for normality was affirmative after applying ANOVA and multiple regression analysis to quantify safety perception of employees in the steel industry. Additionally, the use for normality in this study indicated that the there were no multiple outliers in the data set and that the sample size of 170 was justifiable to use parametric tests. Since the dependent variable was only organisational safety culture, the research adopted the one-way ANOVA. However, their study used seven dimensions of safety culture as independent variables while this study employed five strategies as independent variables for the multiple regression analysis.

\subsubsection{Analysis of variance (ANOVA)}

A set of independent variables whose normality was determined using ANOVA technique showed variability in the outcome. The results were derived using SPSS as shown in Table 3.

Table 3: Analysis of variance of the data

\begin{tabular}{lccccc} 
& Sum of Squares & Degree of Freedom & Mean Square & F-Statistics & Sig \\
\hline Regression & 83,637 & 6 & 12.844 & 17.325 & 0.00 \\
Residual & 128,434 & 162 & 0.702 & & \\
\hline Total & 212,071 & 168 & & & \\
\hline
\end{tabular}

The independent variables used in the analysis were the six management strategies: recruitment; training and development; performance analysis; communication and information; induction and orientation; and reward and compensation, illustrated 83, 637 from the total of 212, 071. The indicative results showed that the dependent variable, organisational safety culture signified $39.44 \%$ of the whole variability of the data. This implies that the remaining $60.56 \%$ representing the sum square of 128 , 434 in the outcome is considered to be unexplained by the independent variables used in this study. Additionally, the p-value of 0.00 is affirmative of the six management strategies and significant influence on the process of entrenching organisational safety culture in the SHE management systems. Thus, demonstrating that there are more independent variables that could have been used and were not included in the regression analysis hence the variability proportion in the outcome.

\subsubsection{Multiple Linear Regression Analysis}

The independent variables used in the study and the dependent variable were used to create the multiple linear regression model. The six independent variables were used in the multiple linear regression formula in a 
collective manner and organisational safety culture as a variable that was dependent.

Table 4: Multiple linear regression estimates

\begin{tabular}{lcccccc}
\hline $\begin{array}{l}\text { Dependent Variable: } \\
\text { Organisational Safety Culture }\end{array}$ & $\begin{array}{c}\text { Unstandardized } \\
\text { Coefficient } \\
\text { Estimate }\end{array}$ & $\begin{array}{c}\text { Standard } \\
\text { Error }\end{array}$ & $\begin{array}{c}\text { Standardized } \\
\text { Coefficient } \\
\text { Estimate }\end{array}$ & T-Statistic & Sig. & VIF \\
\hline Constant & 1.927 & 0.441 & - & 4.520 & 0.000 & - \\
Recruitment & 0.671 & 0.128 & 0.477 & 5.541 & 0.000 & 1.912 \\
Training \& Development & 0.153 & 0.129 & 0.082 & 1.272 & 0.243 & 1.643 \\
Performance Analysis & 0.072 & 0.132 & 0.038 & 0.586 & 0.629 & 1.574 \\
Communication & -0.066 & 0.097 & -0.047 & -0.692 & 0.555 & 1.407 \\
Induction \& Orientation & -0.423 & 0.086 & -0.383 & -5.426 & 0.000 & 1.309 \\
Reward \& Compensation & 0.056 & 0.132 & 0.037 & 0.493 & 0.696 & 2.240 \\
\hline
\end{tabular}

The results of the multiple linear regression from Table 4 shows that the independent variables with high significant diverse effects on organisational safety culture were training and development, and induction and orientation. Additionally, the practice of recruitment was affirmative while induction and orientation indicated a non-affirmative effect on organisational safety culture. Conversely, this implies that an increase in the right recruitment of workers to perform the right jobs leads to a 0.671 increase in organisational safety culture at workplaces. While a reduction in induction and orientation strategies by management tends to reduce organisational safety culture by 0.423 . Training and development, performance analysis, communication and rewards and compensation indicated varied effects not statistically significant. This was because the literature on the use for instance, of rewards and compensation varied. It could be affirmed that the Zambian electricity industry does not reward or compensate appropriately for adherence to SHE procedures.

The standardised coefficient estimates are beta coefficients resulting from the regression analysis that have been homogeneous so that the variances of dependent and independent variables are one (1)
(Wakefield, 2014). The negative beta indicates that there is a decreased use of the dimension in communication, and induction and orientation since the outcome variables decreased by 0.047 and 0.383 respectively.

\subsubsection{Goodness-of-fit and collinearity}

No two or more independent variables with their estimated coefficients are expected to have the same influence on the dependent variable according to the principle of multicollinearity as postulated by Wakefield (2014). This implies that independent variables do not exert the same degree of effect on a given dependent variable. The Variance inflation Factor (VIF) should be below 5 for the non-existence of collinearity. Table 4 shows that none of the six strategies had VIF above 5, implying absence of collinearity between the six independent variables. This confirms that each of the independent variables employs distinctive influence on organisational safety culture.

The multiple linear regression technique is used in determining the fit for adequacies. The R-value in this study as indicated in Table 5 provides the correlation coefficient between the six strategies and organisational safety culture.

Table 5: Goodness-of-fit Statistical Analysis

\begin{tabular}{lllll}
\hline $\mathbf{R}$ & R-Squared & Adjusted R-Squared & Standard Error (S.E) of Estimate & Dublin-Watson \\
\hline 0.637 & 0.387 & 0.354 & 0.885 & 1.809 \\
\hline
\end{tabular}

The correlation coefficient which is the R-Value of 0.637 was found to be of a reasonably high positive correlation. The adjusted R-squared which gives the amount of proportion to which the set of the six independent variables could explain the variations in organisational safety culture is a dependent variable. From this background, the study was indicative of the six strategies which only elucidate $35.4 \%$ of the variations in organisational safety culture; while $64.6 \%$ was nonindicative. This implies that there were certain variables not used in the study that were equally important. Furthermore, a standard error of 0.885 was fairly considerate for the assessed coefficients. The fit for adequacies passed the acceptable threshold of 1.500 to 2.500 as it indicated a Dublin-Watson test statistic of 1.809 .

The specific objectives underpinning the study were namely, to determine management strategies that have an impact on organisational safety culture, to assess worker's knowledge on SHE programs and to establish the effect of organisational safety culture on workers. Various literature was reviewed on management strategies. In analyzing the data, the adoption of ANOVA and multiple linear regression analysis to further explore the data applied six management strategies that include: recruitment, training and development, performance 
analysis, communication and information, induction and orientation and reward and compensation, as independent variables. While organisational safety culture was used as a dependent variable, it can be postulated that the strategies implored in the study have a statistically significant effect on organisational safety culture. A similar analysis was used by Yule (2008) and indicated the need to adopt other independent variables besides the ones used in the analysis. Hence the six factors used in the regression could not elucidate much of the total variability of management strategies in organisational safety culture.

Further to the effects, the results were indicative of recruitment which was positive and induction and orientation which was negative, as being factors that had variability effect on organisational safety culture. This variability could be attributed to the failure of management to induct successfully and orient workers on SHE related issues to promote organisational safety culture. On the other hand, of the remaining four with a positive indication of the effect on organisational safety culture, the study did not adjudge their statistical connotation.

Based on the literature review and the research results the study showed that management, in essence, plays an important and participatory role in inculcating the needed safety requirements in an electricity organisation whose ultimate responsibilities is to ensure safety and health strategies are understood and followed by all workers. As a management strategy, aligning the policies and procedures to the current legal statutes and regulatory requirements such as the OSH Act 36 of 2010 and the Factories Act, Cap 441 of the Laws of Zambia, gives credit of understanding safety values, culture and behaviour from an individual to a country in driving development in a safe environment. Having disclosed in the reviewed literature and the research results that workers are involved in making sure that aspects of SHE are embraced and updated with knowledge and reviewed continuously, it substantiates the existence of knowledge on SHE activities at various workplaces they represent in the electricity industry.

Having noted in the literature reviewed, according to Tan and Nasurdin (2011) and Asiedu-Appiah et al. (2013), that management strategies relate to organisational policies and attitudes, training and development, recruitment and selection, information and communication, performance appraisals and retention, they ensure continuous improvement of organisational safety requirements. Besides these strategies, this study also proposed that the use of information, induction, reward and compensation can also be used as management strategies in entrenching organisational safety culture and safety performance in the electricity industry. Hence, it can be postulated that the strategies examined in the study have a statistically significant effect

\section{References}

Agbola, R. M. (2012). Impact of occupational health and safety management on employee safety. Developing Country Studies, II (9), 156-167. on organisational safety culture and can be used with other strategies recommended in the safety and health body of knowledge by other researchers.

\section{Conclusion}

The overarching aim of the study was to assess the effect of management strategies in entrenching a safety-driven culture in the electricity industry of Zambia to reduce workplace accidents. The study sought to establish knowledge of SHE programs to entrench organisational safety culture in the industry. The study found that recruitment and induction and orientation were cardinal factors that indicated statistical significance of management strategies and had varied effects on organisational safety culture. Further, the results indicated that recruitment had positive effect while induction and orientation factors recorded a negative effect. There was an understanding of safety and health process as tabulated in the OSH Act 36 of 2010 and Factories Act Cap 441 since most of the workers established to being provided with SHE knowledge. Additionally, the study showed that the workers in the electricity industry get fairly involved in SHE related problems. The study's objectives were achieved and were in line with previous research.

The outcome of the study was limited by restriction to the electricity industry, and however, the results can be generalised to other sectors as data collected was only from the players within the electricity industry in Zambia. Additionally, the sample used in the study is a reflection of the representation of the major companies that are in the electricity industry.

It is therefore recommended that similar studies can be pursued outside the confines of the electricity industry in order to attain a longitudinal and comparative study. The study recommends stronger recruitment practices that are appropriate and would have a positive effect on organisational safety culture. The study also recommends restructuring processes during induction and orientation to maintain high levels of safety at workplaces and record fewer workplace accidents. For additional research, it is recommends an exploration and examination of the effects of several other management practices in SHE processes be undertaken.

The findings of the study will significantly contribute to the existing body of knowledge in the area of SHE and management strategies useful in entrenching organisational safety culture in the electricity industry. The recommendations of this study would also be used to strengthen management strategies and improve operations within institutions in the safety and health systems. Lastly, the study would provide the basis for further research in line with management strategies and organisational safety culture in the electricity industry.

Akpan, E. I. (2011). Effective safety and health management policy for improved performance of organization in Africa. International journal of business and management, VI (3), 159-168.

Asiedu-Appiah, F., Kontor, E., \& Asamoah, D. (2013). Effect of human resources management practices on employee retention: Perspective from the mining 
industry. International Research Journal of Arts and Social Sciences, II (2 ), 30-40.

Auditor General. (2015). Report by the Auditor General on the Management of Occupational Safety and Health for the fifth Session of the Eleventh National Assembly, National Assembly of Zambia. 1-99. Lusaka: National Assembly of Zambia.

Bayers, L., \& Rue, L. W. (2011). Human Resource Management (10th ed.). New York: McGraw-Hill Publisher.

Carrillo, A. (2010). Positive safety culture: How to create, lead and maintain. Professional Safety, 55 (5), 4754.

Choudhry, R. M., Fang, D., \& Mohamed, S. (2007). The Nature of Safety Culture: A Survey of the State of the Art. Journal of Safety Science, 45, 993-1012.

Davids, G. T. (2016). Assessing Safety Culture of Professional Pilots within Selected South African Based Aviation Organisations. The University of Western Cape, Faculty of Economics and Management Sciences. South Africa: Western Cape University Library.

Davies, M. B. (2007). Doing a successful research project: using qualitative or quantitative methods. Palgrave, UK: MacMillan Publishers.

Du Toit, W. J. (2012). The Relationship Between Health and Safety and the Human Risk Taking Behaviour in the South African Electrical Construction Industry. Nelson Mandela Metropolitan University. Durban, South Africa: NMMU Library.

Dumas, M. C. (2011). Influence of management's leadership on safety culture: The role of the construction contractors; in Proceedings of the SPE European health, safety and environment conference in oil and gas exploration and production. Proceedings of the SPE European health, safety and environment conference in oil and gas exploration and production, (pp. 22-24). Vienna: Austria.

ERB. (2014). The Energy Regulator. The Energy Regulator Newsletter, 1 (21), 1-20.

Guldenmund, F. W. (2007). The Nature of Safety Culture: A Review of Theory and Research. Safety Science, 45, 215-257.

Haukelid, K. (2008). Theories of (safety) culture revisited-an anthropological approach. Safety Science, 46, 413-426.

Hopkins, A. (2006). Studying organisational Cultures and their Effects on Safety. Safety Science, 44, 875-889.

Impact of health and Safety Management on Employee Safety. (2012). Developing Country Studies, II (9), 156167.

Iqbal, N., Anwar, S., \& Halder, N. (2015). Effect of Leadership Style on Employee Performance. Arabian Journal of Business Management Review, 5 (146).

Kafue Gorge Regional Training Centre. (2014). Effective Management and Safety Study. Lusaka: KGRTC and ZESCO Limited.

Kilian, J. (2012). What is the Role of the HR in Health and Safety Compliance? Retrieved March 28, 2018, from Human Capital Web Site: www.eohumancapital.co.za.

Kwayisi, K. A. (2014). The effect of human resources management practices on health and safety: A case study of the Ghana health service. Accra, Ghana: Nkwame Nkrumah University of Sciences and Technology.
Leedy, P., \& Ormrod, J. (2015). Practical Research: Planning and Design (11th ed.). Essex: Pearson Education Limited.

Machabe, A. P., \& Indermun, V. (2013). Management Perceptions of the Occupational Health and Safety System in Steel Manufacturing Firm. Arabian Journal of Business and Management Review (Nigerian Chapter), 1 (11), 25-36.

Mambwe, M., \& Mwanaumo, E. M. (2017). The Impact of Organisational Safety Culture On Safety Health and Environment (SHE) in Zambia's Electricity Distribution Industry. Proceedings in Joint CIB W099 \& TG59 International Safety, Health and People in Construction Conference. Cape Town, South Africa: Joint Construction in Building.

Mason, R. L., Gunst, R. F., \& Hess, J. L. (1989). Statistical Design and Analysis of Experiments with Applications to Engineering Science. New York: Wiley.

Mihai, M. P., \& Sorin, B. M. (2010). Behavioral Based Safety Management in Electric Power Industry Complementary Safety of Workers. Advances in Automatic Control, Modelling and Simulation, 303 - 307.

Mojapelo, J., Mafini, C., \& Dhurup, M. (2016). Employee Perceptions of Occupational Health and Safety Standards in the Steel Industry. International Journal of Social Sciences and Humanity Studies, 8 (2), 106-121.

Motulsky, I. (2005). Prism 4 Statistics Guide Statistical Analyses for Laboratory and Clinical Researchers. San Diego CA, USA, 2003: GraphPad Software Inc.

Mwanaumo, E. M., \& Thwala, W. D. (2011). A Review of health and Saftey legislation in Botswana relative to construction industry stakeholders. In S. Laryea, R. Leiringer, \& W. Hughs, Proceedings of West Africa Built Environment Research (WABER) Conference, 19-21 July 2011 (pp. 47-57). Accra, Ghana.

National Assembly of Zambia. (2010). Occupational Health and Safety Act No.36 of 2010. Lusaka: GRZ.

Nunez, I., \& Villanueva, M. (2011). Safety capital: The Management of Organisational Knowledge on Occupational Health and Safety. Journal of Workplace Health, 1 (23), 56-71.

Olusuyi, B. O. (2011). Influencing Safety Culture in the UK Offshore Oil and Gas Industry: The Importance of Employee Involvement. Department of Management. Aberdeen: Published Thesis; Aberdeen Business School.

Saunders, M., Lewis, P., \& Thornhill, A. (2009). Research Methods for business students. Harlow: Pearson Education Limited.

Son, C. (2016). Study of Safety Culture Assessment Framework for Process Industries and its Application to a Bayesian Belief Network Analysis. Texas: Submitted to the Office of Graduate and Professional Studies of Texas A\&M.

Tan, C. L., \& Nasurdin, A. M. (2011). Human resource management practices and organizational innovation: Assessing the mediating role of knowledge management effectiveness. Electronic Journal of Knowledge Management, 9 (2), 155-167.

Trochim, B. (2004). Research Methods Tutorials. Retrieved September 30, 2018, from http://www.socialresearchmethods.net/tutorial.htm. 
Wachter, J. K., \& Yorio, P. L. (2014). A system of Safety Management Practices and Worker Engagement for Reducing and Preventing Accidents: An Empirical and Theoretical Investigation. Science Direct, 68, 117130.

Wakefield, J. (2014, September 29). Wiley StatsRef: Statistics Reference Online. Retrieved April 3, 2018, from General and Introductory Statistics: http://www.onlinelibrary.wiley.com

WCFCB. (2016). Worker's Compensation Fund Control Board (WCFCB) Report. Lusaka: WCFCB.
WHO. (2006). World Health Organisation Report. New York: WHO, United Nations.

Williamsen, M. (2007). The culture of safety: Interview with safety pioneer Dan Petersen. Professional safety, 52 (7), 17-27.

Yule, S. (2008). Senior Management Influence on safety performance in the UK and US energy sectors. Scotland: Doctoral thesis: University of Aberdeen.

Zou, P. X., \& Sunjino, R. Y. (2015). Strategic Safety Management in Construction and Engineering. West Sussex: John Wiley \& Sons Ltd. 